\title{
Comment on: "Cytotoxicity of Oxycodone and Morphine in Human Neuroblastoma and Mouse Motoneuronal Cells: A Comparative Approach"
}

\author{
Richard B. Parsons ${ }^{1}$
}

Published online: 25 May 2016

(C) The Author(s) 2016. This article is published with open access at Springerlink.com

One of the most controversial aspects of in vitro drug toxicity testing is the choice of cell model. This is especially true of neurotoxicity testing, where faithful reproduction of the in vivo phenotype is critical for accurate and relevant interpretation of drug toxicity, in particular in relation to clinically relevant compounds. Cell line models are attractive because of their ease of use, their high reproducibility, the high volume of homogeneous cells that can be obtained, and the low cost. In this issue, Kokki et al. [1] have used the SH-SY5Y and NSC-34 cell lines to assess the toxicity of oxycodone, the most commonly used opioid for the treatment of moderate to severe back pain, and compared it to that of morphine, using two standard toxicity assays, 3-(4,5-dimethylthiazole-2-yl)-2,5-diphenyltetrazolium bromide (MTT) and resazurin reduction assays. They report that the toxicity profiles of both compounds are similar, and that the toxicity of oxycodone only occurs at concentrations above the peak clinical concentration in the cerebrospinal fluid after intrathecal administration [1].

Although a well-executed and important study, in order to make conclusions about clinically relevant compounds that will be of relevance to clinicians, one must ensure that the cell model used is as clinically relevant as possible. By their very nature, in vitro cell models do not closely replicate in vivo phenotypes. Instead, all one can strive for is to use a cell model that mimics as closely as possible the

This comment refers to the article available at doi:10.1007/s40268-016-0125-0.

Richard B. Parsons

richard.parsons@kcl.ac.uk

1 Institute of Pharmaceutical Science, King's College London, 150 Stamford Street, London SE1 9NH, UK in vivo phenotype. Advances in primary neurone and stem cell cultures have brought the reality of a clinically relevant neuronal cell model closer, yet they are still not suitable for the majority of neurotoxicity studies published in the literature. As such, the majority of neurotoxicity studies use cell lines as a cell model, with two different cell lines commonly used to demonstrate that any effects observed do not arise from a lack of congruency with the in vivo phenotype, as was done by Kokki and colleagues. But in order for this to be a valid approach, one must use the most clinically relevant cell lines available. This is even more imperative when the cell lines used in a study can easily be made more clinically relevant. The two models chosen and as used by the authors are limited in their clinical relevance as they have not been differentiated prior to neurotoxicity testing. Although widely used in neurotoxicity research, the suitability of SH-SY5Y for neurotoxicity studies is controversial [2]. Although they do demonstrate neuronal characteristics such as the expression of the synaptic marker synaptophysin and their ability to accumulate and release dopamine upon potassium challenge [3], SH-SY5Y cells are a tumour-derived pan-neuronal cell line whose culture conditions can have a significant effect upon their toxic response [4]. Also, one must question whether such neurones would be exposed in vivo to oxycodone by intrathecal administration. The use of NSC-34 cells is a more logical choice; NSC-34 is a motor neurone-like hybrid cell line produced by the fusion of neuroblastoma with mouse motorneuron-enriched primary spinal cord cells $[5,6]$. These cells demonstrate neuronal features such as voltage-gated ion channels, axonal transport and choline acetyltransferase activity, and more closely resemble the type of neurone one would expect to be exposed to oxycodone via intrathecal administration. However, like SH- 
SY5Y, in their undifferentiated state, they possess a tumour rather than a neuronal phenotype $[3,7,8]$.

The use of undifferentiated cells can be desirable; for example, we have used undifferentiated SH-SY5Y cells in our studies to investigate the effects of nicotinamide $\mathrm{N}$ methyltransferase expression upon neuron morphology, biochemistry and neurotoxin susceptibility [3, 9-11], effects that would not have been possible using differentiated SH-SY5Y [12]. However, for the study of Kokki and colleagues, differentiated cells, which have a neuronal rather than tumour phenotype [7, 8], are more clinically relevant than undifferentiated cells and thus would produce more clinically relevant results. Differentiation is easily achieved using a combination of reduction of media serum concentration and supplementation with retinoic acid, producing cells with a terminally differentiated neuronal phenotype as evidenced by increased expression of neuronal markers such as NeuN, and a neuronal morphology as evidenced by the production of neurites [7, 8]. Although there is significant discussion in the literature regarding the degree of differentiation afforded by retinoic acid-based protocols, it is clear that retinoic acid treatment results in the differentation of SH-SY5Y and NSC-34 into phenotypes that are closer to the in vivo neuronal phenotype and as such are a more clinically relevant cell model. The consequence of using these more clinically relevant models is that the relative toxicity profiles and $50 \%$ lethal dose $\left(\mathrm{LD}_{50}\right)$ values of both oxycodone and morphine are likely to be significantly different to those reported in Kokki et al.'s study. For example, compared with undifferentiated cells, differentiated SH-SY5Y cells demonstrate increased sensitivity towards 6-hydroxydopamine [7] and rotenone [13], with decreased sensitivity towards lactacystin [13] and 1-methyl-4-phenyltetrahydropyridinium ion [14], whereas NSC-34 demonstrate reduced sensitivity towards $\mathrm{H}_{2} \mathrm{O}_{2}$, tumour necrosis factor- $\alpha$ and glutamate upon differentiation [6]. Hence, if you are trying to make clinically relevant conclusions about clinically relevant compounds, you must use the most clinically relevant model available, especially when the production of such a model from cells already being used is relatively simple.

\section{Compliance with ethical standards}

Conflict of interest The author has no conflict of interest with respect to this work.

Open Access This article is distributed under the terms of the Creative Commons Attribution-NonCommercial 4.0 International License (http://creativecommons.org/licenses/by-nc/4.0/), which permits any noncommercial use, distribution, and reproduction in any medium, provided you give appropriate credit to the original author(s) and the source, provide a link to the Creative Commons license, and indicate if changes were made.

\section{References}

1. Kokki M, Pesonen M, Vehvilainen P, Litmala O, Pasanen M, Hokki H. Cytotoxicity of oxycodone and morphine in human neuroblastoma and mouse motoneuronal cells: a comparative approach. Drugs R\&D. 2016. doi:10.1007/s40268-016-0125-0.

2. Sarkanen JR, Nykky J, Siikanen J, Selinummi J, Ylikomi T, Jalonen TO. Cholesterol supports the retinoic acid-induced synaptic vesicle formation in differentiating human SH- SY5Y neuroblastoma cells. J Neurochem. 2007;102:1941-52.

3. Thomas MG, Saldanha M, Mistry RJ, Dexter DT, Ramsden DB, Parsons RB. Nicotinamide N-methyltransferase expression in SH-SY5Y neuroblastoma and N27 mesencephalic neurones induces changes in cell morphology via ephrin-B2 and Akt signalling. Cell Death Dis. 2013;4:e669.

4. Thomas MG, Marwood RM, Parsons AE, Parsons RB. The effect of foetal bovine serum supplementation upon the lactate dehydrogenase cytotoxicity assay: important considerations for in vitro toxicity analysis. Toxicol In Vitro. 2015;30:300-8.

5. Almokhtar M, Wikvall K, Ubhayasekera SJ, Bergquist J, Norlin M. Motor neuron-like NSC-34 cells as a new model for the study of vitamin D metabolism in the brain. J Steroid Biochem Mol Biol. 2015. doi:10.1016/j.jsbmb.2015.12.010.

6. Maier O, Bohm J, Dahm M, Bruck S, Beyer C, Johann S. Differentiated NSC-34 motoneuron-like cells as experimental model for cholinergic neurodegeneration. Neurochem Int. 2013;62:1029-38.

7. Lopes FM, Schroder R, da Frota ML, Jr Zanotto-Filho A, Muller CB, Pires AS, Meurer RT, Colpo GD, Gelain DP, Kapczinski F, Moreira JC, Fernandes Mda C, Klamt F. Comparison between proliferative and neuron-like SH-SY5Y cells as an in vitro model for Parkinson disease studies. Brain Res. 2010;1337:85-94.

8. Hiroi A, Yamamoto T, Shibata N, Osawa M, Kobayashi M. Roles of fukutin, the gene responsible for fukuyama-type congenital muscular dystrophy, in neurons: possible involvement in synaptic function and neuronal migration. Acta Histochem Cytochem. 2011;44:91-101.

9. Parsons RB, Aravindan S, Kadampeswaran A, Evans EA, Sandhu KK, Levy ER, Thomas MG, Austen BM, Ramsden DB. The expression of nicotinamide N-methyltransferase increases ATP synthesis and protects SH-SY5Y neuroblastoma cells against the toxicity of Complex I inhibitors. Biochem J. 2011;436:145-55.

10. Liu K, Mistry RJ, Aguirre CA, Fasouli ES, Thomas MG, Klamt F, Ramsden DB, Parsons RB. Nicotinamide N-methyltransferase increases complex I activity in SH-SY5Y cells via sirtuin 3. Biochem Biophys Res Commun. 2015;467:491-6.

11. Milani ZH, Ramsden DB, Parsons RB. Neuroprotective effects of nicotinamide $\mathrm{N}$ - methyltransferase and its metabolite 1-methylnicotinamide. J Biochem Mol Toxicol. 2013;27:451-6.

12. Lopez-Carballo G, Moreno L, Masia S, Perez P, Barettino D. Activation of the phosphatidylinositol 3-kinase/Akt signalling pathway by retinoic acid is required for neural differentiation of SH-SY5Y human neuroblastoma cells. J Biol Chem. 2001;277:25297-304.

13. Jantas D, Roman A, Kusmierczyk J, Lorenc-Koci E, Konieczny J, Lenda T, Lason W. The extent of neurodegeneration and neuroprotection in two chemical in vitro models related to Parkinson's disease is critically dependent on cell culture conditions. Neurotox Res. 2013;24:41-54.

14. Khwanraj K, Phruksaniyom C, Madlah S, Dharmasaroja P. Differential expression of tyrosine hydroxylase protein and apoptosis-related genes in differentiated and undifferentiated SH-SY5Y neuroblastoma cells treated with MPP+. Neurol Res Int. 2015. doi:10.1155/2015/734703. 